\title{
Enraizamento de estacas caulinares e radiculares de cultivares de amoreira-preta coletadas em diferentes épocas, armazenadas a frio e tratadas com AIB
}

\author{
Rooting of stems and root cutting of blackberry cultivars collected in different times, cold storage \\ and treatment with IBA
}

\author{
Marcelo Angelo Campagnolo ${ }^{\mathrm{I}}$ Rafael Pio ${ }^{\mathrm{II}}$
}

\section{RESUMO}

O objetivo do presente trabalho foi avaliar o enraizamento de estacas caulinares e radiculares de cultivares de amoreira-preta, coletadas em diferentes épocas, armazenadas a frio e tratadas com AIB. No primeiro experimento, estacas radiculares e caulinares da amoreirapreta 'Tupy' foram coletadas no momento da poda hibernal, realizada nas seguintes épocas: 07/06, 22/06, 08/07, 22/07, $06 / 08$ e 20/08 de 2009. Já no segundo experimento, metade das estacas caulinares e radiculares da mesma cultivar foi armazenada a frio por 30 dias e a outra metade das estacas foi colocada diretamente para enraizar. Todas as estacas foram tratadas com diferentes concentrações de ácido indolbutírico (AIB): 1000, 2000, 3000 e 4000mg L ${ }^{-1}$ por 10s., além do controle composto somente por água. No terceiro experimento, foram coletadas estacas radiculares das cultivares 'Choctaw', 'Ébano', 'Guarani', 'Arapaho', 'Brazos', 'Cherokee', 'Comanche', 'Caingangue', 'Tupy' e 'Xavante' na poda realizada no dia 22 de junho do ano seguinte. As estacas foram armazenadas a frio por 30 dias e não foi realizado tratamento com AIB. Em ambos os experimentos, as estacas caulinares foram enterradas $2 / 3$ de seu comprimento na posição vertical e as estacas radiculares foram totalmente imersas na posição horizontal, utilizando a vermiculita de grânulos finos como substrato, em telado com sombreamento de 50\%. Após 90 dias, pode-se concluir que as estacas radiculares apresentam melhores resultados, devendo ser armazenadas a frio e não tratadas com $A I B$, mas há diferença do potencial propagativo entre os cultivares de amoreira-preta.

Palavras-chave: Rubus spp., propagação, ácido indolbutírico.

\section{ABSTRACT}

The objective of the present research was to quantify the rizogenic potential of stems and root cuttings of blackberry cultivars, collected in different times, cold storage and treated with indolbutyric acid. In the first experiment, roots and stems cuttings of 'Tupy' blackberry were collected close to it hibernal prune and accomplished in the following times: 07/06, 22/06, 08/07, 22/07, 06/08 and 20/08 of 2009. Already in the second experiment, half of the stems and roots cuttings of 'Tupy' blackberry were submitted to cold storage for 30 days and the other amount of cuttings were placed directly for rooting. The whole cuttings were treated with different concentrations of indolbutyric acid (IBA): 1000, 2000, 3000 and 4000mg L $L^{-1}$ for 10 seconds, and control only for water. In the third experiment, roots cuttings of 'Choctaw', 'Ébano', 'Guarani', 'Arapaho', 'Brazos', 'Cherokee', 'Comanche', 'Caingangue', 'Tupy' and 'Xavante' blackberry cultivars were collected in the pruning accomplished in june 22 of the following year. The cuttings were cold storage for 30 days and treatment was not accomplished with IBA. In both experiments, the stems cuttings were buried $2 / 3$ of its length in the vertical position and the roots cuttings were totally immerged in the horizontal position, using vermiculita as substrate, in greenhouse with $50 \%$ of light. After 90 days, it can be concluded that the roots cuttings presents better results, owing cold storage and without IBA, but there is difference of propagation potential among blackberry cultivars.

Key words: Rubus spp., propagation, indolbutyric acid.

\section{INTRODUÇÃO}

O consumo da amora-preta (Rubus spp.) vem aumentando paulatinamente nos últimos anos devido às características intrínsecas de seus frutos, considerado uma fonte natural rica em antioxidantes e

'Universidade Estadual do Oeste do Paraná (UNIOESTE), Marechal Cândido Rondon, PR, Brasil.

"Universidade Federal de Lavras (UFLA), CP 3037, 37200-000, Lavras, MG, Brasil. E-mail: rafaelpio@dag.ufla.br. Autor para correspondência. 
pigmentos (FERREIRA et al., 2010). O cultivo dessa frutífera no Brasil encontra-se em franca expansão, com resultados promissores em sistema de cultivo agroecológico (ANTUNES et al., 2010). O crescimento dos cultivos brasileiros deve-se também ao custo de implantação e manutenção dos pomares serem relativamente baixos, quando comparado com outras frutíferas perenes cultivadas, evidenciando que essa atividade pode ser mais uma alternativa de renda para agricultura familiar (ATTILIO et al., 2009).

Apesar de a literatura recomendar a utilização de estacas caulinares como fonte de material propagativo, coletadas em plantas durante a poda realizada no inverno (ANTUNES et al., 2000), as estacas radiculares são uma excelente opção e também podem ser utilizadas na produção de mudas da amoreira-preta (ANTUNES, 2002). A vantagem da utilização das estacas radiculares seria quanto ao manuseio, uma vez que a maioria das cultivares comerciais apresenta ramos dotados de espinhos, em números variados, o que onera e dificulta a operação de preparo das estacas.

Pelo fato de as plantas emitirem várias hastes durante a estação de crescimento vegetativo e haver excesso dessas hastes durante a poda de inverno, não haveria limitação quanto à coleta das estacas radiculares. Apesar disso, não há relatos na literatura sobre o potencial rizogênico das estacas radiculares da amoreira-preta, também não há relatos sobre o fato de haver ou não diferença entre o desempenho propagativo em relação às várias cultivares disponíveis no Brasil. Já para as estacas caulinares, a diferença entre a capacidade de emissão de raízes adventícias é marcante. As amoreiras-pretas 'Brazos', 'Guarani', ‘Tupy’, ‘Caingangue’ e 'Ébano’ possuem maior potencial rizogênico, enquanto 'Comanche' e 'Cherokee' apresentam resultados inferiores a 50\% de enraizamento (ANTUNES et al., 2000).

Pode se aproveitar os materiais descartados da poda (ramos) para se confeccionar estacas. Porém, pode ocorrer diferença do potencial rizogênico das estacas em detrimento da época em que as estacas são coletadas em função da época de poda, frente à mobilização dos fotoassimilados ocasionados devido ao mecanismo de dormência que as frutíferas de clima temperado possuem.

Existem algumas técnicas que são empregadas visando ao aumento da emissão de raízes em estacas caulinares e radiculares. Uma delas é o tratamento das estacas em soluções de ácido indolbutírico (AIB). Essa auxina sintética tem por finalidade aumentar a porcentagem de estacas enraizadas, antecipar a iniciação radicular, aumentar o número e a qualidade das raízes formadas e uniformizar o enraizamento (HAN et al., 2009). De acordo com VILLA et al. (2003), o tratamento das estacas caulinares com AIB da amoreira-preta 'Brazos' desfavoreceu o enraizamento das estacas. Porém, esse resultado pode ser divergente em se tratando de estacas radiculares.

Outra técnica que pode ser utilizada é o armazenamento a frio, que possui como finalidade ausentar o material propagativo de luz (estiolamento) ou então suprir a necessidade de frio. $\mathrm{O}$ armazenamento auxilia na superação da endodormência das gemas e propicia aumento da emissão de brotações nas estacas (CELANT et al., 2010; SALIBE et al., 2010). Por sua vez, o estiolamento contribui para induzir a inibição do sistema enzimático AIA-oxidase, aumentando assim a ação da auxina natural AIA nas estacas (BIASI, 1996).

Sendo assim, objetivou-se com o presente trabalho avaliar o enraizamento de estacas caulinares e radiculares de cultivares de amoreira-preta, coletadas em diferentes épocas, armazenadas a frio e tratadas com AIB.

\section{MATERIAL E MÉTODOS}

Foram realizados três experimentos, sendo os dois primeiros simultâneos e o terceiro utilizando os melhores tratamentos resultantes dos dois primeiros e que promoveram resultados superiores. As plantas se localizavam na Fazenda Experimental Antônio Carlos dos Santos Pessoa, pertencente ao Núcleo de Estações Experimentais da Universidade Estadual do Oeste do Paraná (UNIOESTE), no município de Marechal Cândido Rondon-PR.

Nos dois primeiros experimentos, foram coletadas estacas radiculares (padronizadas com $10 \mathrm{~cm}$ de comprimento e diâmetro ao redor de $8 \mathrm{~mm}$ ) e caulinares (estacas lenhosas sem folhas, padronizadas com $15 \mathrm{~cm}$ de comprimento e diâmetro ao redor de $10 \mathrm{~mm}$, sendo efetuado um corte reto no ápice da estaca e outro em bisel na base) da amoreira-preta 'Tupy'. No primeiro experimento, as estacas foram coletadas no momento da poda hibernal, realizada nas seguintes épocas: 07/06, 22/06, 08/07, 22/07, 06/08 e 20/08 de 2009. O delineamento utilizado foi o inteiramente casualizado, utilizando o fatorial 2x6 (tipo de estaca e época de coleta), com quatro repetições e 10 estacas por parcela.

No segundo experimento, metade das estacas foi armazenada a frio por 30 dias (estacas embrulhadas em jornal umedecido e colocadas dentro de sacos plásticos vedados, em câmara tipo BOD a $4^{\circ} \mathrm{C}$ ) 
e a outra metade das estacas foi colocada diretamente para enraizar. Todas as estacas foram tratadas com diferentes concentrações de ácido indolbutírico (AIB) (1000, 2000, 3000 e 4000mg L-1 por 10 segundos, além do controle composto somente por água). O delineamento utilizado foi o inteiramente casualizado, utilizando o fatorial 2x2x5 (tipo de estaca, com e sem armazenamento e concentrações de AIB), com quatro repetições e 10 estacas por parcela.

Em ambos os experimentos, as estacas caulinares foram enterradas $2 / 3$ de seu comprimento na posição vertical e as estacas radiculares foram totalmente imersas na posição horizontal, a $3 \mathrm{~cm}$ de profundidade, em caixas plásticas preenchidas com vermiculita de grânulos finos, localizadas dentro de telado com sombreamento de $50 \%$. As estacas foram diariamente umedecidas manualmente com auxílio de regador e, ao final de 90 dias após o estaqueamento, foram mensuradas a porcentagem de formação de calos, de enraizamento, de brotação e o número médio de raízes emitidas da estaca.

No terceiro experimento, foram coletadas estacas radiculares das cultivares 'Choctaw', 'Ébano', 'Guarani’, ‘Arapaho’, 'Brazos’, ‘Cherokee’, 'Comanche', ‘Caingangue’, ‘Tupy’ e ‘Xavante’ na poda realizada no dia 22 de junho de 2010. As estacas foram armazenadas a frio por 30 dias e, posteriormente, foram totalmente imersas na posição horizontal em caixas plásticas preenchidas com vermiculita de grânulos finos, em telado com sombreamento de $50 \%$. O delineamento utilizado foi o inteiramente casualizado, com 10 tratamentos (cultivares), quatro repetições e 10 estacas por unidade experimental. Após 90 dias, foram mensuradas a porcentagem de formação de calos, de enraizamento, o número médio de raízes emitidas da estaca, a porcentagem de estacas brotadas e o comprimento médio das brotações.

Em ambos os experimentos, os fatores foram submetidos à análise de variância, as médias dos dados qualitativos comparadas pelo teste de Tukey, em nível de $5 \%$ de probabilidade, e os dados quantitativos submetidos à regressão. As análises foram realizadas pelo programa computacional Sistema para Análise de Variância-SISVAR(FERREIRA, 2008).

\section{RESULTADOS E DISCUSSÃO}

Para o primeiro experimento, houve interação entre os fatores tipo e época de coleta das estacas em todas as variáveis mensuradas, sendo que as estacas caulinares coletadas nas duas primeiras épocas e as estacas radiculares coletadas entre 22/06 e 06/08 apresentaram maior porcentagem de formação de calos (Tabela 1). No entanto, o maior enraizamento das estacas da amoreira-preta 'Tupy' ocorreu em estacas radiculares coletadas entre 22/06 e 22/07, com enraizamento variando entre $70 \%$ e $75 \%$. Antes e após esse intervalo, o enraizamento das estacas foi inferior, principalmente na primeira época de coleta das estacas. Porém, na coleta do dia 22/06 foi que ocorreu a maior porcentagem de brotação das estacas radiculares (75\%), as quais apresentam resultados superiores em comparação às estacas caulinares (Tabela 1). Contudo, a emissão do maior número de raízes ocorreu nas estacas radiculares coletadas entre 22/07 a 06/08, com tendência de ser superior em relação às estacas radiculares coletadas em 22/06.

Pelo exposto, percebe-se que o enraizamento das estacas radiculares foi superior em comparação às estacas caulinares e que a porcentagem de enraizamento e brotação dessas estacas foi incrementada quando essas foram coletadas no início do período hibernal, nas condições subtropicais do Oeste paranaense. Isso pode estar relacionado ao fato de que, no início do período de repouso vegetativo, ocorre mobilização dos fotoassimilados para o sistema radicular, que auxiliam no enraizamento das estacas radiculares. Conforme relata HAN et al. (2009), reservas mais abundante de carboidratos correlacionam-se com maiores porcentagens de enraizamento e sobrevivência das estacas.

No segundo experimento, não houve interação entre os fatores de armazenamento a frio e tipo de estacas nas avaliações realizadas, mas houve diferença quanto ao armazenamento a frio e com as concentrações de AIB, quanto as mensurações das porcentagens de formação de calos, de enraizamento e de brotação das estacas.

Estacas radiculares armazenadas a frio apresentaram maior porcentagem de formação de calos (100\%), enraizamento (89,3\%), brotação (91\%) e número médio de raízes emitidas (13), em comparação às estacas caulinares (Tabela 2). Analisando os resultados obtidos, percebe-se que o armazenamento influenciou positivamente a rizogênese das estacas radiculares, já para as estacas caulinares o contrário ocorreu. A qualidade do sistema radicular formado nas estacas radiculares da amoreira-preta 'Tupy' armazenada a frio por 30 dias e, posteriormente, colocada para enraizar, sem o tratamento com AIB, pode ser observada na figura 1. Percebe-se que houve elevada ramificação das raízes emitidas nas estacas radiculares quando essas foram armazenadas a frio (Figura 1B), em comparação 
Tabela 1 - Porcentagem de estacas caulinares e radiculares com formação de calos, enraizadas, brotadas e número médio de raízes em amoreira-preta 'Tupy' coletadas em diferentes épocas durante o período invernal ${ }^{(1)}$. Marechal Cândido Rondon, UNIOESTE, 2011.

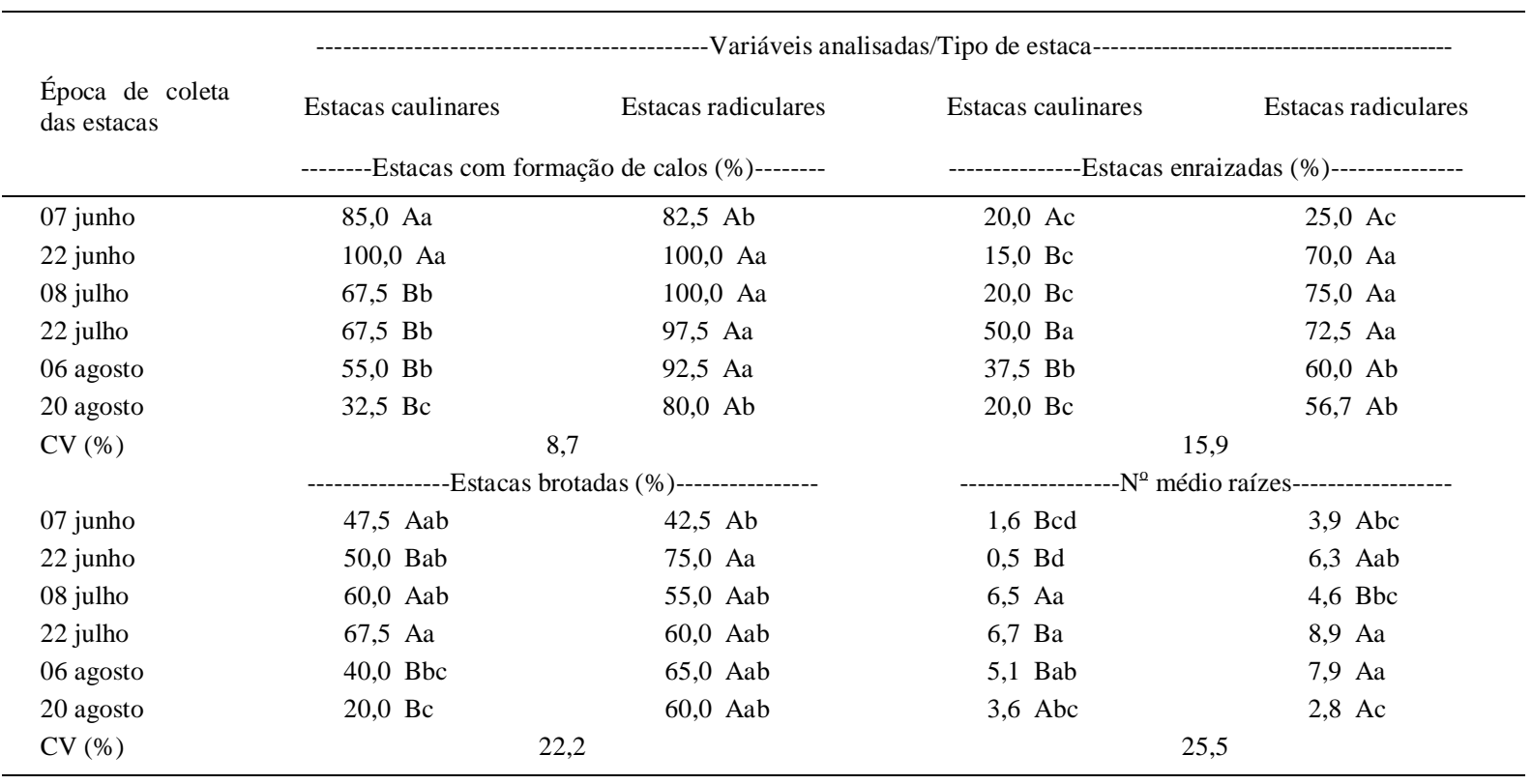

${ }^{(1)}$ Médias seguidas pela mesma letra em minúscula na coluna não diferem entre si pelo teste Tukey $(\mathrm{P} \leq 0,05)$.

às estacas radiculares que não passaram pelo armazenamento (Figura 1A).

Pelo exposto, o armazenamento a frio das estacas radiculares incrementou em $20,8 \%$ o enraizamento e $36 \%$ a brotação das estacas, além de proporcionar o aumento de mais de seis raízes emitidas (Tabela 2). Segundo CELANT et al. (2010), a exposição das estacas a baixas temperaturas auxilia na superação da endodormência das gemas das estacas e na brotação. $\mathrm{O}$ armazenamento em baixas temperaturas ainda contribui para o aumento da emissão das raízes, pois o estiolamento das estacas aumenta a presença de compostos fenólicos, como o ácido clorogênico, floroglucinol, ácido caféico e catecol, inibidores da síntese da AIA-oxidase, aumentando assim a ação da auxina natural AIA nas estacas (BIASI, 1996).

Com o tratamento das estacas em concentrações crescentes de AIB, ocorreu redução linear da porcentagem de formação de calos, de enraizamento e de brotação das estacas (Figura 2).

Tabela 2 - Porcentagem de estacas caulinares e radiculares com formação de calos, enraizadas, brotadas e número médio de raízes em amoreira-preta 'Tupy' armazenadas ou não a frio $\left(4^{\circ} \mathrm{C}\right)$ por 30 dias $^{(1)}$. Marechal Cândido Rondon, UNIOESTE, 2011.

\begin{tabular}{|c|c|c|c|c|}
\hline \multirow{2}{*}{$\begin{array}{l}\text { Armazenamento das } \\
\text { estacas a frio }\end{array}$} & Estacas caulinares & Estacas radiculares & Estacas caulinares & Estacas radiculares \\
\hline & \multicolumn{2}{|c|}{--------Estacas com formação de calos (\%)-------- } & \multicolumn{2}{|c|}{----------------Estacas enraizadas (\%)--------------- } \\
\hline Sem armazenamento & $57,0 \mathrm{Ba}$ & $87,5 \mathrm{Ab}$ & 40,0 Аа & 68,5 Ab \\
\hline Com armazenamento & $28,5 \mathrm{Bb}$ & 100,0 Аа & $18,5 \mathrm{Bb}$ & 89,3 Аа \\
\hline \multirow[t]{2}{*}{ CV (\%) } & \multicolumn{2}{|c|}{7,8} & \multicolumn{2}{|c|}{14,0} \\
\hline & \multicolumn{2}{|c|}{---------------Estacas brotadas (\%)--------------- } & \multicolumn{2}{|c|}{ 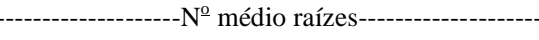 } \\
\hline Sem armazenamento & 55,0 Аа & $55,0 \mathrm{Ab}$ & 4,0 Аа & $7,1 \mathrm{Ab}$ \\
\hline Com armazenamento & $7,2 \mathrm{Bb}$ & 91,0 Аа & $1,9 \mathrm{Bb}$ & 13,3 Аа \\
\hline CV (\%) & \multicolumn{2}{|c|}{17,2} & \multicolumn{2}{|c|}{21,6} \\
\hline
\end{tabular}

${ }^{(1)}$ Médias seguidas pela mesma letra em minúscula na coluna não diferem entre si pelo teste Tukey $(\mathrm{P} \leq 0,05)$. 


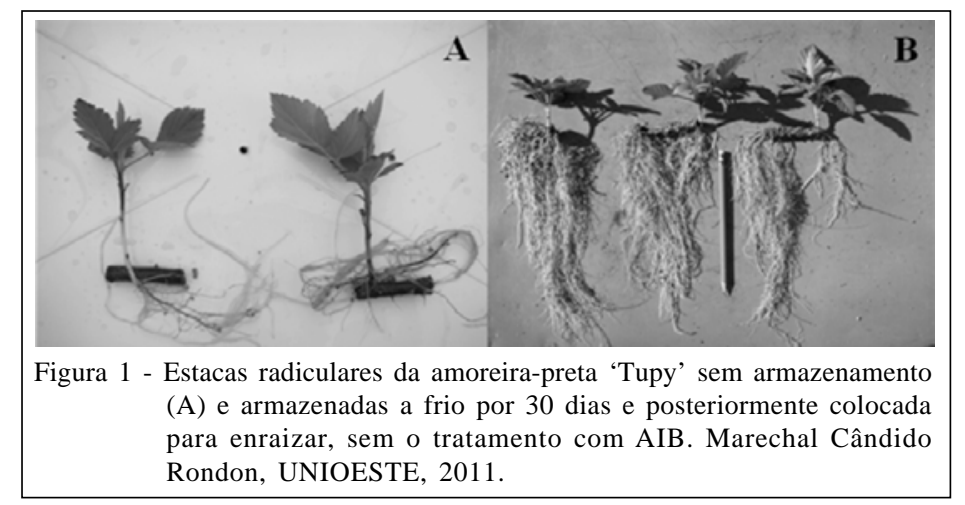

A não utilização do ácido indolbutírico propiciou 72\% de formação de calos, $64 \%$ de estacas enraizadas e $59 \%$ de estacas brotadas. Esses resultados concordam com VILLA et al. (2003), que constataram que o tratamento das estacas caulinares da amoreira-preta 'Brazos' desfavoreceu o enraizamento das estacas.

Já no terceiro experimento, houve diferença estatística entre as cultivares de amoreira-preta em todas as mensurações realizadas. As estacas radiculares das amoreiras-pretas 'Ébano’, ‘Arapaho’, 'Comanche' e 'Tupy’ apresentaram mais de 97\% de formação de calos (Tabela 3). Porém, dessas, somente as três últimas citadas apresentaram a maior emissão de raízes (entre 11 e 14 raízes, aproximadamente) e junto com 'Caingangue', apresentaram a maior porcentagem de estacas enraizadas.

Pelo exposto, percebe-se que há diferença no potencial rizogênico das estacas radiculares entre as cultivares de amoreira-preta. Esses resultados concordam com ANTUNES et al. (2000), que verificaram diferença no potencial rizogênico das estacas caulinares de amora-preta.

Para as mensurações relativas às brotações, as estacas radiculares das amoreiras-pretas 'Brazos', 'Cherokee', 'Comanche’, 'Caingangue’ e 'Tupy' apresentaram a maior porcentagem de brotação, mas foi 'Arapaho', Cherokee' e 'Comanche' que tiveram maior comprimento médio das brotações, acima de $13 \mathrm{~cm}$ (Tabela 3). Acredita-se que as estacas dessas cultivares já possam ser plantadas a campo, decorridos os 90 dias de enraizamento, não necessitando ser transplantadas para sacolas plásticas para as mudas se desenvolverem antes no pré-plantio, uma vez que as brotações apresentam um comprimento satisfatório e as raízes emitidas das estacas ramificaram (Figura 1).

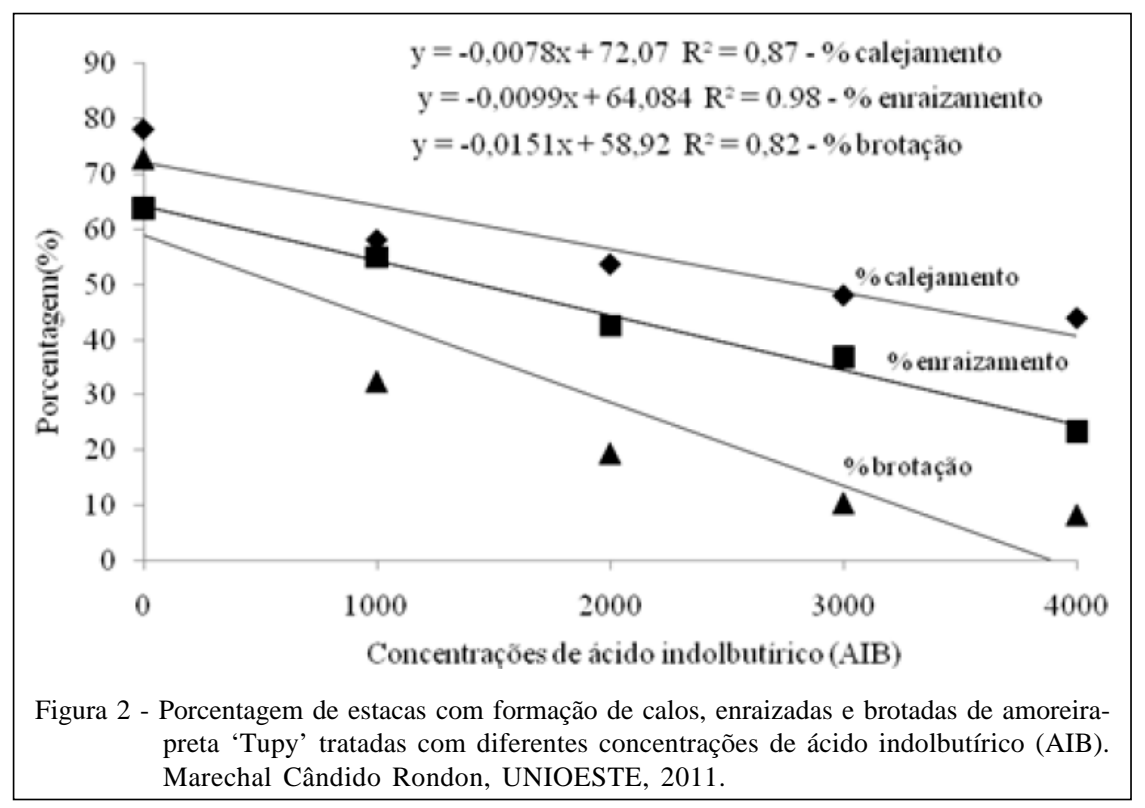

Ciência Rural, v.42, n.2, fev, 2012. 
Tabela 3 - Porcentagem de estacas radiculares com formação de calos, enraizadas, número médio de raízes, porcentagem de estacas brotadas e comprimento médio das brotações em diferentes cultivares de amoreira-preta ${ }^{(1)}$. Marechal Cândido Rondon, UNIOESTE, 2011.

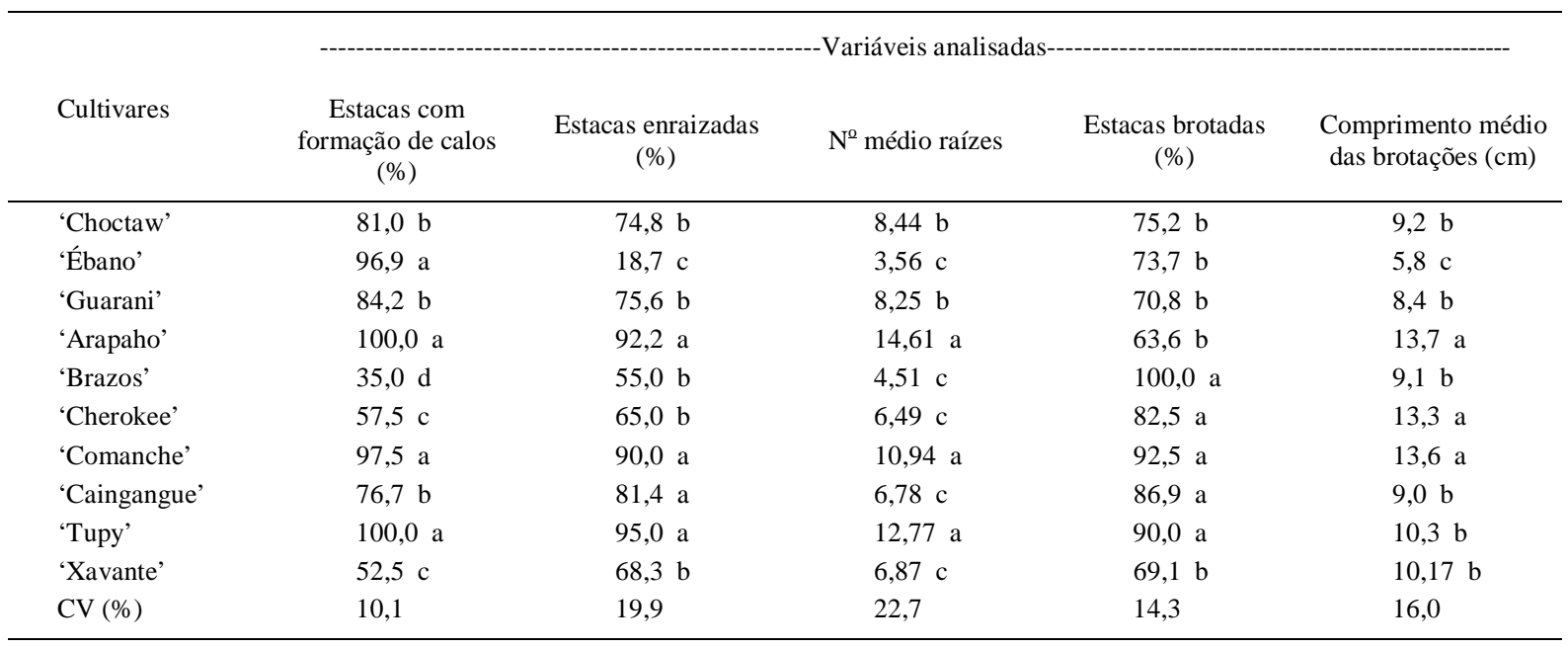

${ }^{(1)}$ Médias seguidas pela mesma letra em minúscula na coluna não diferem entre si pelo teste Tukey $(\mathrm{P} \leq 0,05)$.

\section{CONCLUSÃO}

Estacas radiculares apresentaram maior potencial de enraizamento quando comparadas com estacas caulinares; estacas coletadas no início do período invernal apresentam maior enraizamento; o armazenamento a frio auxiliou no incremento do enraizamento e brotação das estacas; o tratamento com AIB desfavoreceu o enraizamento e a brotação das estacas; as estacas radiculares das cultivares 'Arapaho', 'Comanche' e 'Tupy' apresentam maior emissão de raízes e brotos.

\section{AGRADECIMENTO}

Ao Conselho Nacional de Desenvolvimento Científico e Tecnológico (CNPq), pelo auxílio financeiro.

\section{REFERÊNCIAS}

ANTUNES, L.E.C. et al. Fenologia e produção de cultivares de amoreira-preta em sistema agroecológico. Ciência Rural, v.40, n.9, p.1929-1933, 2010. Disponível em: <http:// www.scielo.br/scielo.php?script=sci_arttext\&pid=S01034782010000900012\&lng=pt\&nrm $=$ iso $>$. Acesso em: 27 jul. 2011. doi: 10.1590/S0103-84782010000900012.

ANTUNES, L.E.C. Amora-preta: nova opção de cultivo no Brasil. Ciência Rural, v. 32, n.1, p.151-158, 2002. Disponível em: $<$ http://www.scielo.br/scielo.php?script=sci_arttext\&pid=S0103$84782002000100026 \& \operatorname{lng}=p t \& n r m=i s o \& t \operatorname{lng}=p t>$. Acesso em: 27 jul. 2011. doi: 10.1590/S0103-84782002000100026.

ANTUNES, L.E.C. et al. Propagação de cultivares de amoreirapreta (Rubus spp.) através de estacas lenhosas. Revista Brasileira de Fruticultura, v.22, n.2, p.195-199, 2000.

ATTILIO, L.B. et al. Custo de produção de amora-preta em região tropical. Revista Brasileira de Fruticultura, v.31, n.4, p.1042-1047, 2009. Disponível em: <http://www.scielo.br/ s ci elo.php? script =s ci_art text \& pid = S $0100-$ 29452009000400017\&lng=pt\&nrm=iso $>$. Acesso em: 27 jul. 2011. doi: 10.1590/S0100-29452009000400017.

BIASI, L.A. Emprego do estiolamento da propagação de plantas. Ciência Rural, v.26, n.2, p.309-314, 1996. Disponível em: <http://www.scielo.br/scielo.php?pid=S010384781996000200025\&script=sci_arttext $>$. Acesso em: 27 jul. 2011. doi: 10.1590/S0103-84781996000200025.

CELANT, V.M. et al. Armazenamento a frio de ramos portaborbulhas e métodos de enxertia de cultivares de marmeleiro. Ciência Rural, v.40, n.1, p.20-24, 2010. Disponível em: <http:/ /www.scielo.br/scielo.php?script=sci_arttext\&pid=S010384782010000100004\&lng=pt\&nrm=iso $>$. Acesso em: 27 jul. 2011. doi: 10.1590/S0103-84782009005000223.

FERREIRA, D.F. SISVAR: um programa para análises e ensino de estatística. Revista Symposium, v.6, p.36-41, 2008.

FERREIRA, D.S. et al. Compostos bioativos presentes em amorapreta (Rubus spp.). Revista Brasileira de Fruticultura, v.32, n.3, p.664-674, 2010. Disponível em: <http://www.scielo.br/ scielo.ph p ? s cript = sci_art text \& pid = S $0100-$ 29452010000300004\&lng=pt\&nrm=iso >. Acesso em: 27 jul. 2011. doi: 10.1590/S0100-29452010005000110.

HAN, H. et al. A review on the molecular mechanism of plants rooting modulated by auxin. African Journal of Biotechnology, v.8, n.3, p.348-353, 2009.

SALIBE, A.B. et al. Enraizamento de estacas do porta-enxerto de videira 'VR 043-43' submetidas a estratificação, ácido indolbutírico e ácido bórico. Bragantia, v.69, n.3, p.617-622, 2010. Disponível em: <http://www.scielo.br/scielo.php?script=sci_arttext\&pid=S0006$87052010000100013 \& \operatorname{lng}=p t \& n r m=i s o>$. Acesso em: 27 jul. 2011. doi: 10.1590/S0006-87052010000100013.

VILLA, F. et al. Propagação de amoreira-preta utilizando estacas lenhosas. Ciência e Agrotecnologia, v.27, n.4, p.829-834, 2003. Disponível em: <http:/www.scielo.br/scielo.php?script=sci_arttext\&pid=S1413$70542003000400013 \& \operatorname{lng}=p t \& n r m=i s o \& t l n g=p t>$. Acesso em: 27 jul. 2011. doi: dx.doi.org/10.1590/S1413-70542003000400013. 